\title{
Ecological Management of (Geo)ecological Risks in Gas Industry
}

\author{
Vladimir N. Bashkin ${ }^{1,2, *}$ and Rauf V. Galiulin ${ }^{3}$ \\ ${ }^{1}$ Gazprom VNIIGAZ LLC, Razvilka, Leninsky District, Moscow Region, 142719 Russia \\ ${ }^{2}$ Institute of Physicochemical and Biological Problems of Soil Science RAS, Pushchino, Moscow Region, 142292 Russia \\ ${ }^{3}$ Institute of Basic Biological Problems RAS, Pushchino, Moscow Region, 142292 Russia
}

\begin{abstract}
It is shown in the given paper that the definitive aspect of gas industry sustainable development is a well defined scientifically substantiated strategy which represents, to a large extent, the art of management based on long-term forecasts. This task can be fulfilled by developing an adequate systems analysis methodology where the gas industry is seen as a complex graph decomposed into separate subsystems for further investigation. Formulation of gas industry sustainable development strategy aimed at finding and validating the optimum balance between gas production and consumption and ensuring harmonious and synchronous development of the industry subsystems, cannot be completed without a relevant methodology. While developing the methodology, it is critical to apply geo-information systems, in which by synthesizing various data, can display the entire information on the long-term gas industry development programs. To estimate cost-effectiveness of gas industry sustainable development strategy fundamental principles are applied. They include modeling of cash flows associated with implementation of different projects and the need to consider fluctuations in the field of development costs and results generated in different periods of time using discounted cash flows. Since systemic risks management is a multi-stage iterative process with a corresponding risks analysis as its core component risks should be assessed and managed in consistency with multiple scenarios of the gas industry development. And, finally, the strategy implementation requires assessment of the geo-ecological risks associated with interaction of the 'gas industryenvironment' system and quantitative methods for identifying and assessing the probability of risk occurrence.
\end{abstract}

Keywords: Gas industry chain, geoecological risks, classification, ecological management

\section{INTRODUCTION}

General classification of geo-ecological (geo-environmental) risks associated with the gas industry is directly linked to its structure and consistent with the scheme designed to disintegrate the gas industry into subsectors acting as individual subsystems (Bashkin 2006; Samsonov et al. 2007; Bashkin \& Priputina, 2010; Bashkin et al. 2013; Bashkin 2014). As a result,geo-ecological risks may be structured at a lower level related to the corresponding subsystems of the gas industry. In terms of the systems analysis and classification principles, each single subsector is a complex subsystem requiring further decomposition and differentiation into lower classification levels. It's worthy to consider in more detail the process of differentiating various types of risk for separate subsystems with regard to their diversity and origin (classifying between geophysical, physical, chemical, biogeochemical, production, financial economic and social risks).

*Address correspondence to this author at the Institute of Physicochemical and Biological Problems of Soil Science RAS: Moscow Region, 142292 Russia; Tel: +7 916 860-20-38; Fax: + 7 4967-33-05-95,

E-mail: Bashkin@issp.serpukhov.su

\section{CLASSIFICATION OF GEO-ECOLOGICAL RISKS FOR GAS INDUSTRY}

Taking into account the gas production chain, better to start from geological surveys.

In geological surveys the probability of occurrence of different types of geo-ecological risks in the 'gas industry environment' system depends on how various categories of resources and reserves are interrelated in gas-bearing provinces. The types of risks are shown schematically in Fig. (1).

The diagram is based on qualitative and quantitative changes of interdependent influence within the 'geological surveys - environment' subsystem since the probability of geo-ecological risks coming from seismic surveys and exploration well drilling depends on the operations at the 'resource' or 'reserves' stage.

Structuring of geo-ecological risks associated with the environmental impact assessment therefore, depends on the category of natural gas resources. Thus, when geological surveys are conducted at the stage of proving resources in gas-bearing provinces, physical geo-ecological risks are likely to occur, caused by seismic surveys and potential tectonic changes (Ampilov 2003, 2003a, 2004). At the initial stage of prospective reserves build-up seismic surveys may 


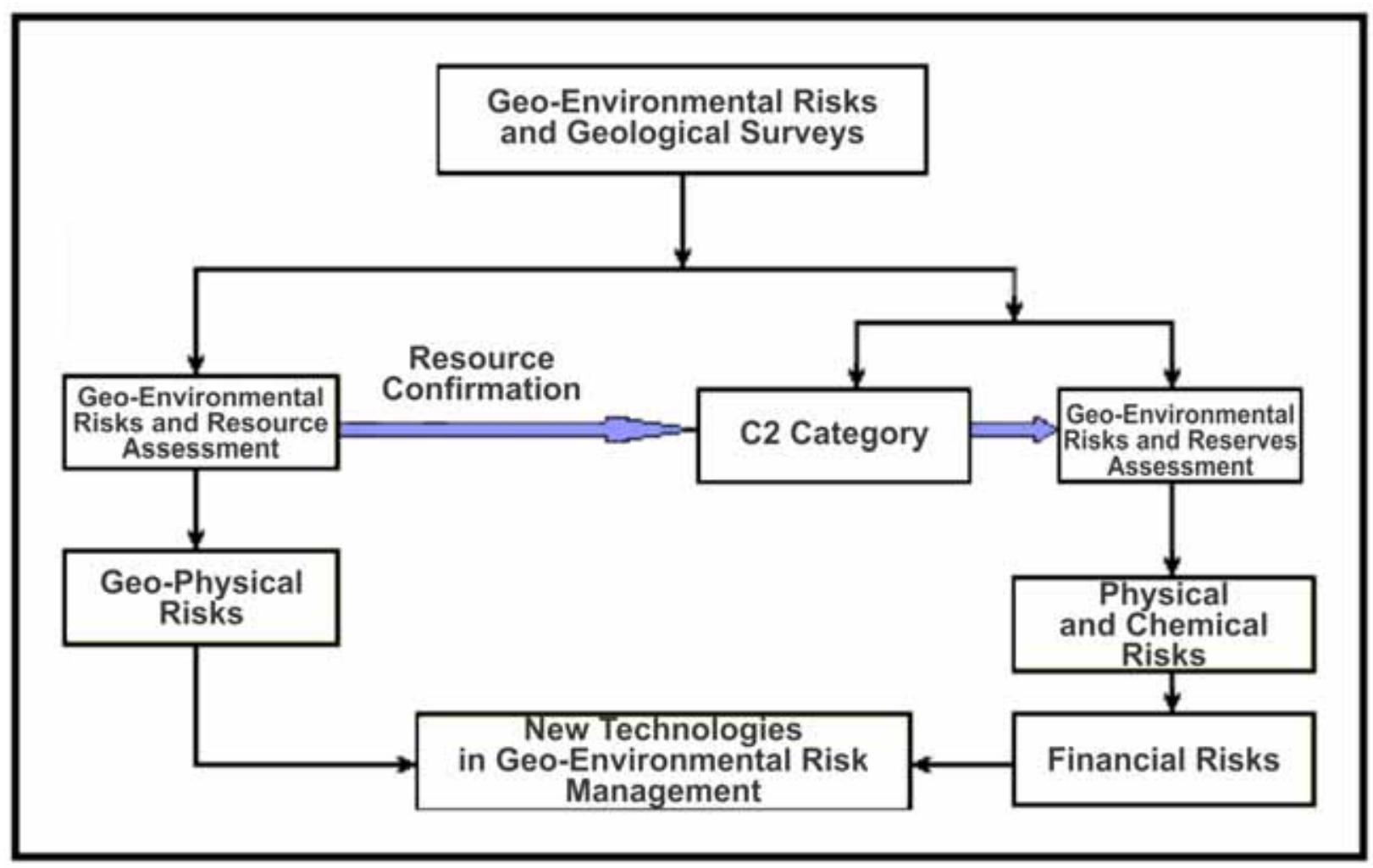

Fig. (1). Nature of geo-ecological risks (GER) at geological surveys.

be coupled with the risk of synergistic effects on the tectonic structure particularly in labile zones, for instance, in the Northern Sakhalin and the Caspian Sea areas where geoecological risks belong to the geophysical type.

The stage of proving reserves involves exploration drilling at depths of 2,000 to 5,000-6,000 m which can cause physical-bearing and chemical-bearing geo-ecological risks. The most significant are the following:

1) physical-bearing risks arising from engineering and environmental support of exploration activities (soil deformation in the course of road construction resulting in erosion, solifluction, thermokarst, etc.);

2) geophysical-bearing and chemical-bearing risks associated with drilling activities (use of drilling fluids, well washing, gas condensate and oil collection in the designated tanks, etc).

Although the geo-ecological risks of the geophysicalbearing type associated with geological surveys differ depending on the natural conditions, they have some commonality. For instance, in vulnerable environments such as offshore and coastal areas of the Arctic Ocean and the Caspian Sea, exploration drilling should be totally waste free presupposing complete removal and disposal of different wastes at specially designated and equipped sites.

Furthermore, during geological surveys and development of new gas-bearing provinces, the probability of geoecological risk occurrence largely depends on the financial capacities of risk management with application of state-of- the-art technologies. Such risks can arise from developing different fields in the Arctic regions and offshore areas of the northern seas (the Shtockman gas and condensate field, the Yamal Peninsula, the $\mathrm{Ob}$ and Taz Bays). That is all due to the lack of specialized equipment such as ice-resistant drilling rigs, sub-sea production and gas pumping units, and necessary environmental protection technologies as well as excessively high cost of projects which lead to unjustified financial risks.

With regard to the geo-ecological risk classification gas production subsystem should be differentiated at the stage of field development and operation (Golubchikov 2006). The risks are thus divided into those associated with the environmental impact of production facilities and feedbackassociated risks (Fig. 2). The geo-ecological risks occurring due to well drilling and construction and from industrial and domestic facilities are attributed to concentrated risks, while those associated with field and inter-field pipelines and access roads are linear risks. At the field operation stage the geo-ecological risks are mainly deconcentrated along the area.

Below is a classification of chemical geo-ecological risks associated with the impact of pollutants emission from the gas production facilities.

The risks that may occur at the field development stage are:

1) well construction accidents;

2) technogenic impact of construction equipment; 


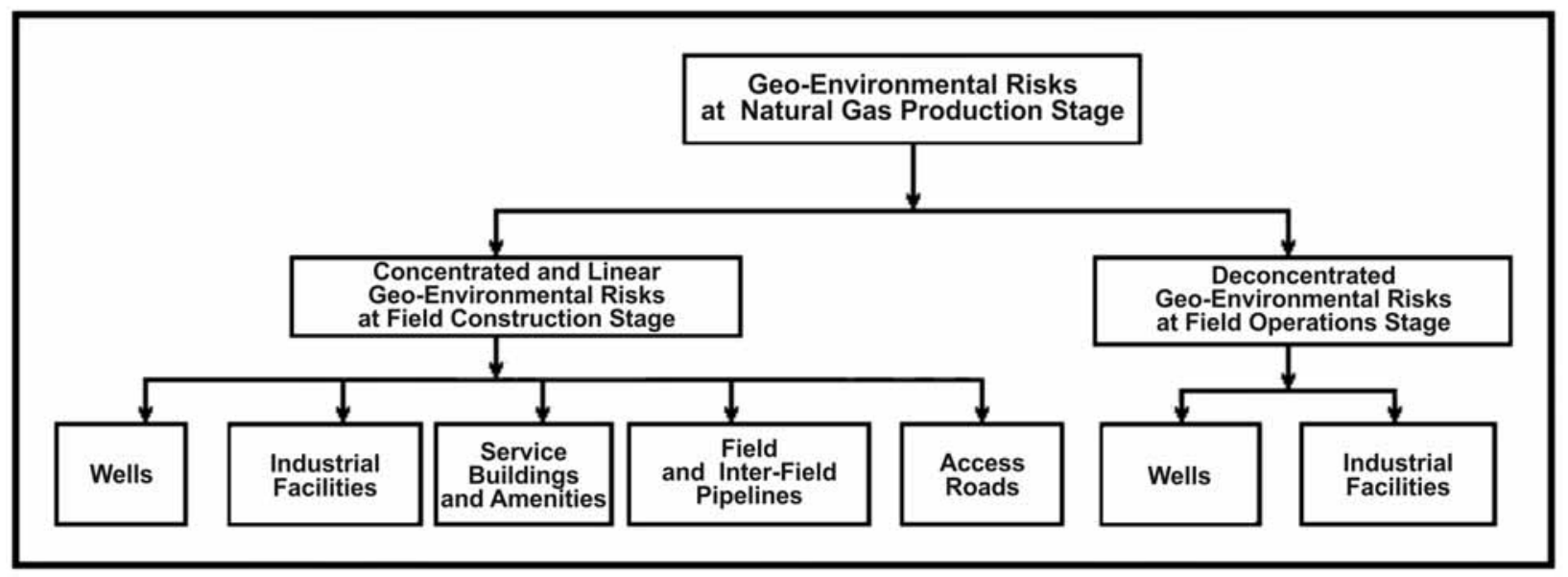

Fig. (2). Types of geo-ecological risks (geo-environmental risks, GER) in gas production subsystem.

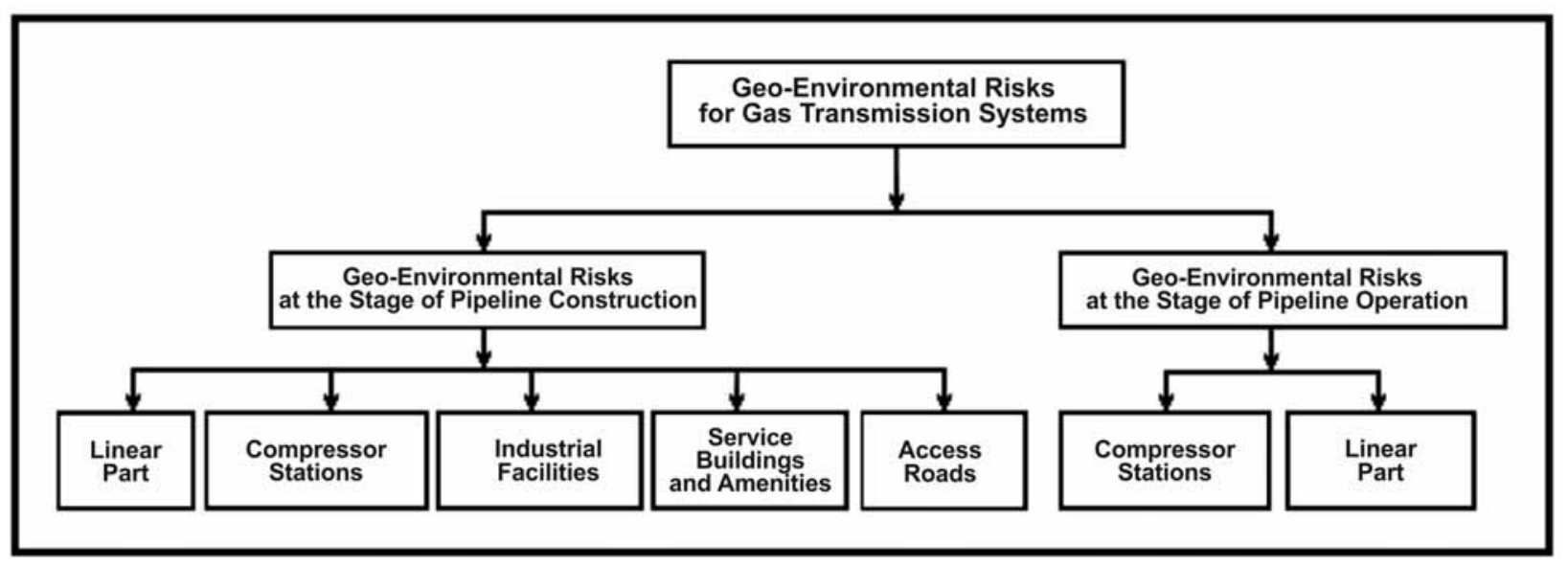

Fig. (3). Types of geo-ecological risks ((geo-environmental risks, GER) for gas transmission subsystem.

3) technogenic impact of the facilities;

4) seawater intrusion.

The risks that may occur at the field operation stage are:

1) accidents at industrial facilities, including wells;

2) condensate spills (in gas and condensate fields);

3) pollutant emissions from natural gas flaring;

4) well blowing;

5) gas leaks.

The geo-ecological risks in the 'gas production - environment' subsystem may arise due to the local peculiarities of gas production facilities (located in the northern or southern provinces) and the specificity of gas production in the onshore, offshore and sub-sea fields.

Launch of new natural gas fields gives rise to construction of new trunk pipelines and, consequently, to significant changes in gas flows and requires differentiation of various factors underlying the geo-ecological risks. Thus, as in the case of gas production facilities it is feasible to classify geoecological risks associated with gas transmission at the stages of pipelines construction and operation (Fig. 3).
The gas transmission system scope in the Russian Federation determines its high priority in the geo-ecological risks assessment in gas industry. The subsystem components such as compressor stations, industrial facilities, service buildings and amenities exert concentrated impact on the environment, while pipelines and access roads create linear impact (Bashkin et al. 2002).

Differentiation between various types of risks is made in consistency with diverse effects that gas transmission facilities have on the environment. The highest probability of chemical-bearing geo-ecological risks is associated with operation of gas turbine drives at trunk pipeline compressor stations since gas fuel accounts for $80 \%$ of the total consumption for technical needs.

It is also worth considering feedback effects of geoecological risks on the gas transmission system, to assess the corresponding chemical, biological, biogeochemical and physical risks.

Below is classification of the chemical-bearing risks that may occur at the stage of gas pipeline construction and operation. 
Among the risks associated with gas pipeline construction are:

1) accidents occurring at the stage of installation and testing of pipeline linear sections, gas pumping machines and additional equipment;

2) technogenic effects at the stage of gas transmission facilities construction, such as erosion, solifluction, landslides, water regime modification, alteration of the specially protected nature territories regime, impact on animal migration etc.;

3) pollutant emissions from construction equipment.

Among the risks associated with gas pipeline operation are:

1) accidents at industrial facilities such as compressor stations and pipeline linear sections;

2) gas leaks in compressor stations and pipeline linear sections;

3) pollutant emissions from natural gas flaring at compressor stations;

4) thermal effects in the permafrost areas subject to thermokarst processes.

Geo-ecological risks are attributed to the following:

1) physical and chemical risks that cause corrosion damages to pipelines due to exposure to an aggressive medium;

2) physical and mechanical risks that cause pipeline ruptures due to different kinds of soil deformation including landslides, solifluction, thermokarst, subsidence, surface erosion, water scours, etc.;

3) geophysical risks that cause tectonic and geodynamic damages to gas pipeline integrity.

A study has been made to analyze the time-space distribution of accidents occurring in the pipeline networks within the East European Platform along with certain parameters that reflect the current geodynamic activity of the Platform. It showed that emergency situations were closely linked with geo-structural deformations of the earth crust and depended on the Platform activity periods and its oscillatory movements (Parshikova et al.. 2004).

When classifying the geophysical, chemical, biological, biogeochemical and physical risks that may occur in the underground gas storage facilities, it is important to consider both the negative effects on the environment and impact of the risks on the condition of the facilities at the stage of their construction and operation. Among the interdependent geoecological risks are:

1) water regime modification caused by construction of underground gas storage facilities;

2) change in seismic and geodynamic characteristics of some potential gas industry provinces including Sakhalin, the Irkutsk Oblast, the Caspian Sea area;

3) gas emissions from underground storage tanks.

The interdependent geo-ecological risks in the 'gas processing - environment' subsystem include: tion);

1) environmental pollution (air, soil, natural water pollu-

2) impact on human health;

3) social environmental risks;

4) risks associated with the construction and operation of gas processing facilities in severe natural climatic conditions, for instance, construction of liquefied natural gas plants beyond the Arctic Circle;

5) production risks associated with the use of low pressure gas.

\section{REGIONAL FACTOR OF GEO-ECOLOGICAL RISKS EXPOSURE IN 'GAS INDUSTRY-ENVIRONMENT SYSTEM'}

The above specified regularities and factors of geoecological risks development in the gas industry and interdependence of different technological processes in its separate sectors require detailed description and structuring at the local level. As we have already mentioned, potential gas fields are located in the northern and southern regions of the Russian Federation and are divided into:

a) onshore fields in the Irkutsk Oblast, the Krasnoyarsk Krai, the Republic of Sakha Yakutia, etc.;

b) nearshore (coastal) fields on the Yamal Peninsula, the Sakhalin Island, in the Astrakhan Oblast;

c) offshore fields: the Shtockman gas and condensate field, fields in the North Caspian, the Ob-Taz Bay, etc .

These fields are different in terms of the regional geological, climatic and technogenic factors. So are the conditions under which the geo-ecological risks occur in the "gas industry - environment" system.

The main regional factors that may induce geo-ecological risks cover all the existing and potential natural and maninduced processes and their development (within the period of forecast gas industry development, e.g. until 2030). It is practical to identify these factors by determining fields' limits, gas pipeline routes, the locations of underground gas storage facilities and gas processing plants. Parameters of the man-induced processes are defined as a part of the master scheme for the gas industry development, pre-investment feasibility studies, pre-project and technical documentation. In terms of systemic analysis, this stage is defined as decomposition stage.

The next stage considers exposure to the cross effect of natural and man-induced processes. This is done at the local, regional, trans-regional, and trans-boundary levels. This approach indicates that the exposure may have a multilayer nature due to pollutants migration with air, water and terrigenous flows and shift of air, water and terrigenous mass (Rogozin 2003). As such, the following natural factors of geo-ecological risks are taken into account:

1) seismic activity involving division into earthquakeprone areas with magnitude over 6 on the Richter scale and non earthquake-prone areas with magnitude under 6; 
2) existence of geo-structural elements of the first order (platforms) including structures of the second order (shields, massifs, plates), orogenes singling out structural elements of the second order (epiplatformic, intermediate, and epigeosynclinal) and riftogenes;

3) orographic roughness with roughness depths of $<10$ to $>600 \mathrm{~m}$;

4) current rate of vertical crustal movements ranging from $>[+14]$ to $>[-14] \mathrm{mm} / \mathrm{yr}$;

$5)$ status of gas-bearing geological rocks.

All the above factors may be classified in line with the water temperature regime for zones and subzones:

1) by the frost penetration level: permafrost, seasonal frost, continuous or sporadic iciness, absence of frost penetration;

2) by the humidity level: humid, semi-humid, dry and arid conditions.

Interdependence of geo-ecological risks is attributable to the man-induced processes occurring in the above-specified gas industry subsystems.

\section{CONCLUSION}

Thus, the definitive aspect of gas industry sustainable development is a well defined scientifically substantiated strategy, which represents, to a large extent, the art of management based on long-term forecasts. This task can be fulfilled by developing an adequate systems analysis methodology where the gas industry is seen as a complex graph decomposed into separate subsystems for further investigation. Formulation of gas industry sustainable development strategy aimed at finding and validating the optimum balance between gas production and consumption and ensuring harmonious and synchronous development of the industry subsystems, cannot be completed without a relevant methodology. While developing the methodology it is critical to apply geo-information systems, which by synthesizing various data, can display the entire information on the long-term gas industry development programs. To estimate cost-effectiveness of gas industry sustainable development strategy fundamental principles are applied. They include modeling of cash flows associated with implementation of different projects and the need to consider fluctuations in field development costs and results generated in different periods of time using discounted cash flows. Since systemic risks manage- ment is a multi-stage iterative process with a corresponding risks analysis as its core component risks should be assessed and managed in consistency with multiple scenarios of the gas industry development. And, finally, the strategy implementation requires assessment of the geo-ecological risks associated with interaction of the 'gas industry-environment' system and quantitative methods for identifying and assessing the probability of risk occurrence.

\section{CONFLICT OF INTEREST}

The authors confirm that this article content has no conflict of interest.

\section{ACKNOWLEDGEMENTS}

The authors express their deep appreciation and gratitude for their affiliation institutions, namely Institute of physicalchemical and biological problems of soil science RAS and Institute of basic biological problems RAS for the support during research and development.

\section{REFERENCES}

Ampilov, YP (2002) Economic-Geological Modeling of Resources and Oil Reserves with Account of Uncertainties and Risk, Geoinformmark Publishers, Moscow.

Ampilov, YP (2003) Reserves Valuation, Geoinformmark, Moscow.

Ampilov, Y P (2004) Seismic Interpretation: Experience and Problems, Geoinformmark Publishers, Moscow.

Bashkin, VN (2006) Modern Biogeochemistry, $2^{\text {nd }}$ edition, Springer, Dordrecht.

Bashkin, VN \&, Priputina, IV (2010) Ecological Risk Management at Emission of pollutants, Gazprom VNIIGAZ Moscow.

Bashkin, VN, Arno, OB, Arabsky, AK, Barsukov, AV, Priputina, IV \& Galiulin, RV (2013) Retrospective and Prognosis of Geoecological Situation in the Gas-condensate Fields of the Polar Regions, Gazprom VNIIGAZ, Moscow.

Bashkin, VN (2014) Biogeochemistry of Polar Ecosystems in the Impacted Zones of Gas Industry, Gazprom VNIIGAZ, Moscow.

Golubchikov, MY (2006) Geo-environmental aspects of varandey peninsula development. Energy, 6, 59-61.

Bashkin, VN, Kazak, AS, Snakin, VV \& Priputina, IV (2002) Ecosystems Sustainability to Trunk Pipelines Emissions, Universum, MoscowSmolensk.

Parshikova, N, Rudakov, V \& Rakitina, G (2004) Geo-Deformation Factor in Assessing Emergencies in Gas-Distributing Systems. FEC Technologies.

Rogozin, AL (2003) Assessment and Natural Risk Management, Kruk, Moscow. Samsonov, RO, Kazak, AS \& Bashkin, VN (2007) Master Plan Methodology for Gas Industry Development, Scientific World. Moscow.

\footnotetext{
Received: January 12, $2015 \quad$ Revised: March 01, $2015 \quad$ Accepted: March 12, 2015

(C) Bashkin and Galiulin; Licensee Bentham Open.

This is an open access article licensed under the terms of the Creative Commons Attribution Non-Commercial License (http://creativecommons.org/ licenses/by-nc/3.0/), which permits unrestricted, non-commercial use, distribution and reproduction in any medium, provided the work is properly cited.
} 